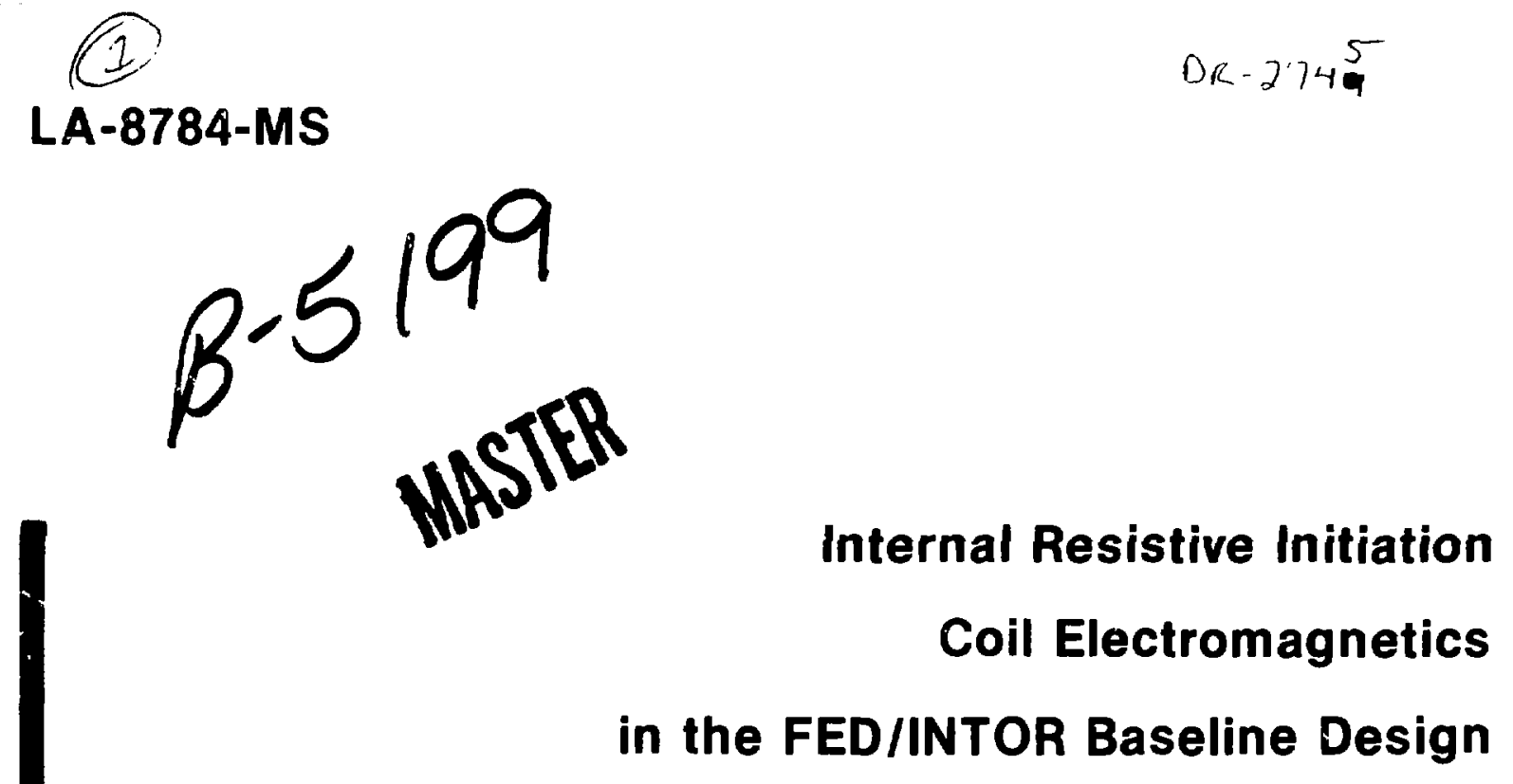
in the FED/INTOR Baseline Design 


\title{
INTERNAL RESISTIVE INITIATION COIL ELECTROMAGNETICS IN THE FED/INTOR BASELINE DESIGN
}

\author{
by
}

\author{
H. F. Vogel, George Bronner, and John G. Murray
}

\begin{abstract}
This study determined some of the electric requirements for radjo-frequency nonassisted plasma initiation from normal conducting coils inside tokamak toroidal field coils in the presence of cryostats and other major structures. We also studied the effects of bellows or highly insulated sections. Depending on whether or not insulating sections are used, the field penetration time is 50 to $90 \mathrm{~ms}$, the blip pulse length is 0.15 to $0.19 \mathrm{~s}$, and the power supplied to the blip coils is 400 to $700 \mathrm{MW}$. Because of its plasma stabilizing effect, a highly conducting vacuum shell is recommended.
\end{abstract}

\section{INTRODUCTION}

This study was made to determine some of the electric requirements for plasma current initiation from internal and normal conducting coils in the presence of cryostats and other major structures. Eddy current losses. induced voltages, and effects of bellows or highly insulating sections are determined.

The induced cuirents in the Fusion Engineering Device or International Tokamak Reactor (FED/INTOR) structures will be important in the design of the vacuum vessel. This is true in machines now being constructed. and it will be more important for FED/INTOR because of a thicker vacuum vessel, large areas for neutron-shield material, added cooling piping, the great amount of stored energy associated with the plasma current, and increased requirements for maintainability.

Initiation, as well as a major fast disruption with the plasma current vanishing in $20 \mathrm{~ms}$, causes the following.

- Large currents are induced in structures, which by mut:sal interaction generate forces and torques on adjacent coils and structures. The toroidal induced currents interact with the steady-state vertical or horizontal fields to provide electromagnetic forces. Similarly, radially directed currents induced in the structures, particularly in the sector end plates, interact with the toroidal field to produce large forces and torques on each segment of the vacuum vessel. If the construction arrangement of the vacuum-vessel segments results in arcs or currents at right angles to the toroidal field, erosion and large forces or torques occur on the segments.

- A voltage is induced in external poloidal coils that can cause damage to insulation. The superconducting coil terminals limit the allowable induced voltage.

- The superconductor operztion requires a safe margin between the superconducting state and the normal state. Induced eddy currents increase the required safety margins in the toroidal fitsld (TF) coils. The heat generated by eddy currents in structures at superconducting temperatures increases the cooling requirements.

- If the induced structure currerics result in arcs between sectors of the vacuum vessel, erosion, proportional to the transferred electric charge, may result. Damage may be particularly severe in the coolant piping system and may result in an increase in the impurity level in the vacuum vessel. On the 
other hand, a vacuum-vessel shell with high con ductivity near the plasma may provide a path for the image currents to stabilize the plasma. Conversely, the initiation and control power requirements become more severe in the presence of a high-conductivity shell.

The voltage ( $100 \mathrm{~V}$ for $0.10 \mathrm{~s}$ ) required for plasma initiation can be obcained by induction from the ohmic heating $(\mathrm{OH})$ poloidal circuit or from a special "blip" coil. A simplified Engineering Test Facility or Internal Tokamak Reactor (ETF/1NTOR) study ${ }^{1}$ on a similar topic showed the energy supplied to the initiation pulse was $180 \mathrm{MJ}$ when fed through the $\mathrm{OH}$ coil versus 40 to $60 \mathrm{MJ}$ when fed through the blip coils. Our study is confined to the latter arrangement. The $\mathrm{OH}$ induced voltage will be 5 V/turn with a blip coil; without a blip coil. the required $\mathrm{OH}$ driving voltage is $357 \mathrm{~V} /$ turn. The blip coil can be installed to couple closely with the plasma so that it need not be superconducting. The induced voltage in the $\mathrm{OH}$ and poloidal field (PF) superconducting coils may be less for most coils, because the blip coil couples less to the superconducting coils than to the plasma.

The FED/INTOR baseline design whose linear dimensions are shown in Fig. 1 is the basis of this study. All passive conductors in the structure are effectively thin when compared with the skin depth in a plasma startup puise. Hence. for pulse analysis. the passive conductors are subdivided only in their long radial or axial dimension.

Table I shows the structural elements and some of their characteristics. including the resistance of each. Those elements whose resistance is varied to determine the effect of including bellows or insulating sections are marked in the table. Circular symmetry and the existence of a magneric flux normal midplane are always assumed.

\section{METHOD}

By the finite difference method of the POISSON code. the self- and mutual inductances are computed in the configuration shown in Fig.l. The self- and mutual inductances lead to a matrix of dimension 48, where all self- and mutual inductances are integrated over both of the tokamak's symmetrical halves, above and below the midplane. To provide an easily understood summary of the 48 th-order matrix, we show in Table II the matrix reduced to the 17 elements with generic significance defined in Table I. With the 48 subelements and their electromagnetic couplings $\mathbf{M}_{1, j}$, we write our set of differential equations whose integration is discussed in the text following.

$$
\begin{aligned}
& 0=R_{1}(t) I_{1}+L_{1} i_{1}+\sum_{j=2}^{4 \theta} M_{1, J} i_{J} \\
& 0=R_{2} I_{2}+L_{2} I_{2}+\sum_{j \times 2} M_{2, J} i_{J}
\end{aligned}
$$

$$
\begin{aligned}
& V_{41}=R_{41} I_{41}+L_{41} \dot{I}_{41}+\sum_{j \times 41} M_{41 . J} \dot{I}_{J} \\
& V_{42}=R_{42} I_{42}+L_{42} \dot{I}_{41}+\sum_{j \times+2} M_{42, J} \dot{I}_{J} \\
& 0=R_{43} I_{43}+L_{43} \dot{I}_{43}+\sum_{j \times 43 . j} M_{43 . J} \dot{I}_{1}
\end{aligned}
$$

$$
0=R_{48} I_{48}+L_{48} \dot{I}_{48}+\sum_{J=1}^{47} M_{48, J} \dot{I}_{1} .
$$

Some of the resistances $R_{1}$ are changed as indicated in Table I to account for the high-resistance sections.

The plasma resistance is defined in the time function

$R_{1}(t)= \begin{cases}\alpha t^{-1}, & t \leqslant 0.01 \mathrm{~s} \\ \beta t^{-1.6674}, & t \geqslant 0.01 \mathrm{~s} .\end{cases}$

where $\alpha=150 \mu \Omega \mathrm{s}$ and $\beta=6.94 \mu \Omega \mathrm{s}^{1.6674}$. The loop voltage measured at the plasma surface is a function of the current $I_{1}$ and its time derivative, and all three are obtained by integrating the system of Eqs. (1), that is.

$V_{D}=I_{1} R_{1}(t)+L_{\text {int }} i_{1}$

where $\mathrm{L}_{\mathrm{lnt}} \simeq \mu_{\mathrm{o}}(\mathrm{b} / 4)=2.04 \mu \mathrm{H}$ is the internal plasma inductance ( $b$ is the major radius). Equation (2) is strongly specialized because it is obtained by fitting one cxponential function to the plasma current and another exponential function to the plasma's resistive voltage as 


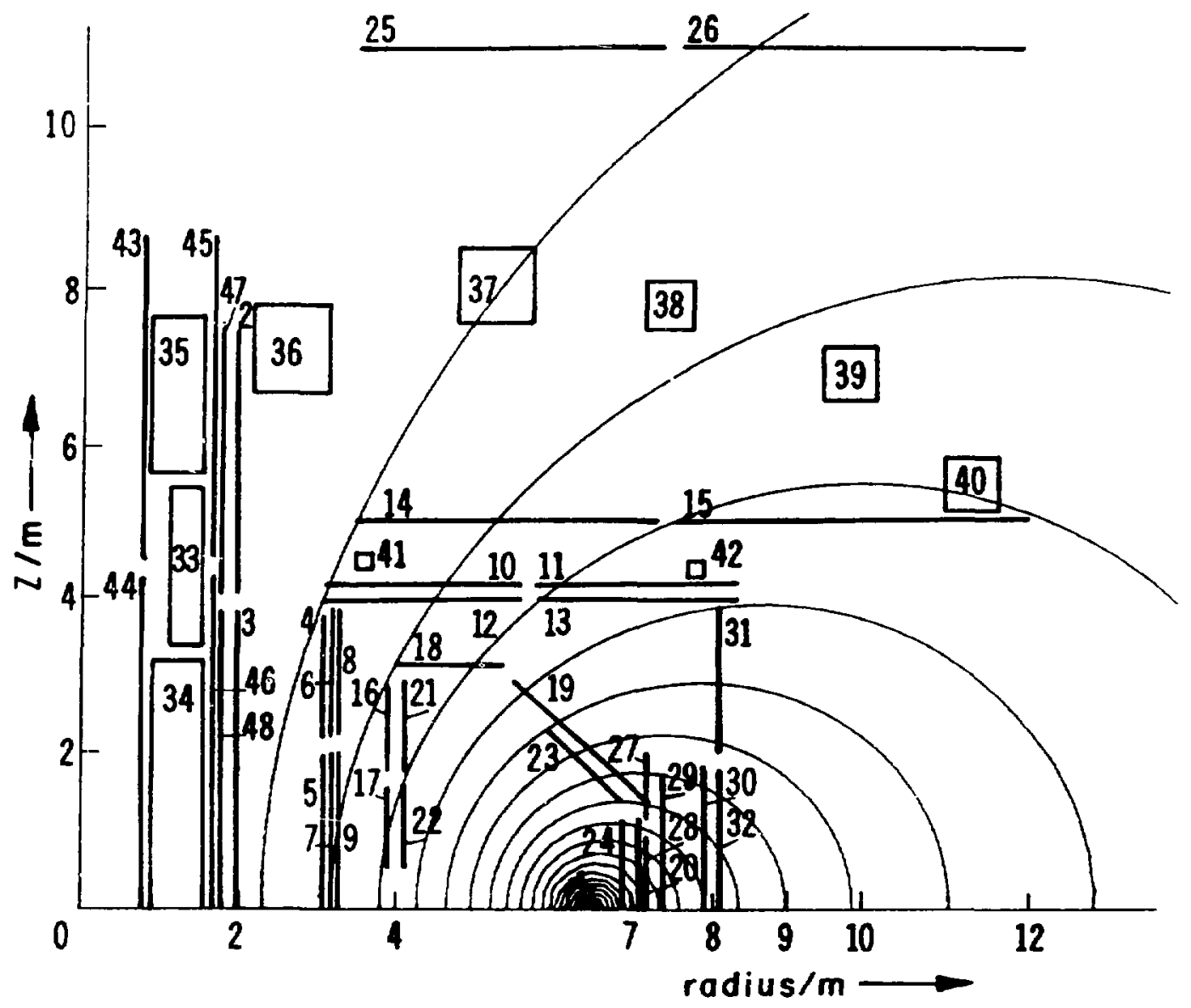

Fig. 1.

Configuration and plasma field of the FED/INTOR baseline design. The labels are defined in Table I.

discussed in Ref. 3 and shown in Fig. 2. In Fig. 2, we added the plots of our approximation, which consist of exponential functions fitted at $t=0.01$ and $1.0 \mathrm{~s}$. For the time interval $\mathrm{t}<0.01 \mathrm{~s}$, we used Peng's ${ }^{3}$ suggested $90-V$ value for the term $I_{1} R_{1}(t)$. Thus, the current rise is constant, $\dot{I}_{1}(t)=0.6 \mathrm{MA} / \mathrm{s}$. This specialization is used to include the electromagnetic details in the given initiation-scenario calculations. Consequently. the blip voltage $V_{41}, V_{42}$ is determined so that $I(t)=0.6$ $\mathrm{MA} / \mathrm{s}$. The artificial constraint $\mathrm{V}_{41}=\mathrm{V}_{42}$ is applied because there is no assumption on wheiher one or two blip coils should be used. The number of ampere turns required may thus be found for the blip coil set: all of our computations are based on the single turn coil set.

\section{RESULTS}

Figure 3 shows the current in all active coils and the plasma current in Data Case I. that is, for no added resistance (no high-resistance section) when the voltage $V_{41}=V_{\Delta z}=115 \mathrm{~V} /$ turn is applied as a step function. The plasma current rise is delayed by $\tau_{d} \simeq 90 \mathrm{~ms}$. To overcome a significant part of this delay, ould apply an overvoltage to the system, but the required voltage peak would then be impractical. The delay is caused by slow field penetration, so one may simply delay by $\tau_{d}$ those operations in the initiation scenario that are not coupled to the electromagnetic field, such as the gas injection. The delays $\tau_{d}$ are listed in Table III for five 
TABLE I

ACTIVE AND PASSIVE CONDUCTORS

\begin{tabular}{|c|c|c|c|c|c|}
\hline $\begin{array}{l}\text { Subelements } \\
\text { As Labeled } \\
\text { In Fig.1 }\end{array}$ & $\begin{array}{l}\text { Element } \\
\text { Number }\end{array}$ & $\begin{array}{c}\text { Element } \\
\text { Designation }\end{array}$ & Material & $\begin{array}{l}\text { Thickness } \\
\text { (cm) }\end{array}$ & $\begin{array}{c}\text { Resistance } \\
\text { Above or } \\
\text { Below } \\
\text { Midplane } \\
2 R_{1} \\
(\mathrm{~m} \Omega)\end{array}$ \\
\hline 1 & 1 & Plasma (20 cm rad.) & & & $R_{1}(\mathbf{t})$ \\
\hline $2,3,47,48$ & 2 & $\begin{array}{l}\text { Bucking cyl. for } \\
\text { TF coils }\end{array}$ & S.S. ${ }^{c}$ & 1.0 & 0.0101 \\
\hline $4,5,14,15,25,26$ & 3 & TF dewar & S.S. & 1.0 & $0.124^{\mathrm{b}}$ \\
\hline 6,7 & 4 & Spool & S.S. & 1.5 & 0.250 \\
\hline 8,9 & $5^{\mathrm{a}}$ & Inner wall & S.S. & 1.5 & 0.255 \\
\hline $10-13$ & 6 & Spool top, shell top & S.S. & $1.5,1.0$ & 0.402 \\
\hline $16 \cdot 20$ & $7^{8}$ & Plasma shell & S.S. & 1.0 & 0.328 \\
\hline 21.22 & 8 & Graphite & Graphite & 2.0 & 0.685 \\
\hline 23.24 & $9^{\mathrm{a}}$ & Water pipe & S.S. & 1.0 & 0.936 \\
\hline $27 \cdot 30$ & $10^{8}$ & Breeder blanket & S.S. & $1.0,0.5$ & 0.879 \\
\hline 31,32 & $11^{\mathrm{B}}$ & Outer shell & S.S. & 1.0 & 0.940 \\
\hline 33 & 12 & $\mathrm{OH}$ coil & S.C. ${ }^{d}$ & -- & 0 \\
\hline 34 & 13 & EI coil & S.C. & $\cdots$ & $\mathbf{0}$ \\
\hline $35-37$ & 14 & ED coils & S.C. & $\cdots$ & 0 \\
\hline $38-40$ & 15 & EO coils & S.C. & --- & D \\
\hline 41.42 & 16 & Blip coils & Copper & $\cdots$ & 0.00955 \\
\hline 43-46 & 17 & $\mathrm{OH}$ dewar & S.S. & 1.0 & $0.0286^{b}$ \\
\hline
\end{tabular}

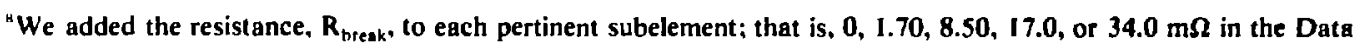
Case I, II, III. IV, or V. respectively, above the midplane, and the same $R_{\text {break }}$ to the image element below the midplane.

"Room temperature value.

'Stainless steel.

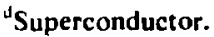

data cases. In the following equation, $\tau_{d}$ is assumed to be compensated by the operation. Hence, $t-\tau_{d}$ is substituted for $t$ in Eq. (2), thus

$$
R_{1}(t)=\left\{\begin{array}{lr}
150 \Omega, & t-\tau_{d} \leqslant 10^{-6} s \\
a\left(t-\tau_{d}\right)^{-1}, & 10^{-6} \geqslant t-\tau_{d} \leqslant 0.01 \mathrm{~s} \\
\beta\left(t-\tau_{d}\right)^{-1.6674}, & t-\tau_{d} \geqslant 0.01 \mathrm{~s} .
\end{array}\right.
$$

Figures 4 and 5 show the resulting currents and voltages for Data Case 1. Figures 6 and 7 show the resulting currents and voltages for Data Case IV, where two voltages are given in each plasma-voltage graph. The plots labeled "V-plasma" are for the plasma voltage $V_{p}$ in Eq. (3), and "V-circuit-1" is given by

$\mathbf{I}_{1} R_{1}(t)+L_{1} \dot{I}_{1}$

which is the electromotance (EMF), except for the sign. All other voltages similarly plotted are the respective EMFs. A summary of the blip voltage $V_{b}$, the sum $I_{b}$ of 


\section{TABLE II}

\section{COUPLING COEFFICIENTS AND SELF INDUCTANCES}

Coupling Coefficients

\begin{tabular}{|c|c|c|c|c|c|c|c|c|c|c|c|c|c|c|c|c|c|}
\hline Circuit & 1 & 2 & 3 & 4 & 5 & 6 & 7 & 8 & 9 & 10 & 11 & 12 & 13 & 14 & 15 & 16 & 17 \\
\hline 1 & 1.000 & & & & & & & & & & & & & & & & \\
\hline 2 & 0.118 & 1.000 & & & & & & & & & & & & & & & \\
\hline 3 & 0.237 & 0.307 & 1.000 & & & & & & & & & & & & & & \\
\hline 4 & 0.207 & 0.433 & 0.461 & 1.000 & & & & & & & & & & & & & \\
\hline 5 & 0.215 & 0.419 & 0.455 & 0.813 & 1.000 & & & & & & & & & & & & \\
\hline 6 & 0.266 & 0.267 & 0.577 & 0.355 & 0.367 & 1.000 & & & & & & & & & & & \\
\hline 7 & 0.483 & 0.302 & 0.492 & 0.534 & 0.555 & 0.562 & 1.000 & & & & & & & & & & \\
\hline 8 & 0.274 & 0.304 & 0.386 & 0.579 & 0.603 & 0.368 & 0.676 & 1.000 & & & & & & & & & \\
\hline 9 & 0.553 & 0.178 & 0.378 & 0.299 & 0.310 & 0.455 & 0.745 & 0.392 & 1.000 & & & & & & & & \\
\hline 10 & 0.526 & 0.148 & 0.344 & 0.245 & 0.255 & 0.398 & 0.680 & 0.320 & 0.744 & 1.000 & & & & & & & \\
\hline 11 & 0.473 & 0.145 & 0.366 & 0.236 & 0.245 & 0.417 & 0.637 & 0.305 & 0.688 & 0.782 & 1.000 & & & & & & \\
\hline 12 & 0.282 & 0.133 & 0.427 & 0.198 & 0.206 & 0.535 & 0.465 & 0.247 & 0.466 & 0.465 & 0.523 & 1.000 & & & & & \\
\hline 13 & 0.377 & 0.122 & 0.333 & 0.196 & 0.203 & 0.371 & 0.519 & 0.252 & 0.556 & 0.622 & 0.754 & 0.489 & 1.000 & & & & \\
\hline 14 & 0.075 & 0.637 & 0.200 & 0.265 & 0.257 & 0.183 & 0.190 & 0.186 & 0.114 & 0.095 & 0.093 & 0.088 & 0.079 & 1.000 & & & \\
\hline 15 & 0.113 & 0.205 & 0.455 & 0.137 & 0.140 & 0.345 & 0.223 & 0.141 & 0.189 & 0.173 & 0.187 & 0.235 & 0.172 & 0.154 & 1.000 & & \\
\hline 16 & 0.150 & 0.093 & 0.541 & 0.118 & 0.123 & 0.341 & 0.254 & 0.141 & 0.244 & 0.242 & 0.273 & 0.338 & 0.262 & 0.064 & 0.329 & 1.000 & \\
\hline 17 & 0.199 & 0.261 & 0.492 & 0.276 & 0.282 & 0.659 & 0.400 & 0.264 & 0.333 & 0.302 & 0.323 & 0.446 & 0.292 & 0.220 & 0.302 & 0.309 & 1.000 \\
\hline
\end{tabular}

Self Inductances

$(\mu \mathrm{H})$

\begin{tabular}{ccccccccccccccccccccccc}
\hline 1 & 2 & 3 & 4 & 5 & 6 & 7 & 8 & 9 & 10 & 11 & 12 & 13 & 14 & 15 & 16 & 17 \\
\hline 32.5 & 11.4 & 100.7 & 14.0 & 14.8 & 90.5 & 141.7 & 26.2 & 54.6 & 74.5 & 72.5 & 17.8 & 23.8 & 2.9 & 39.5 & 70.2 & 33.5 \\
\hline
\end{tabular}




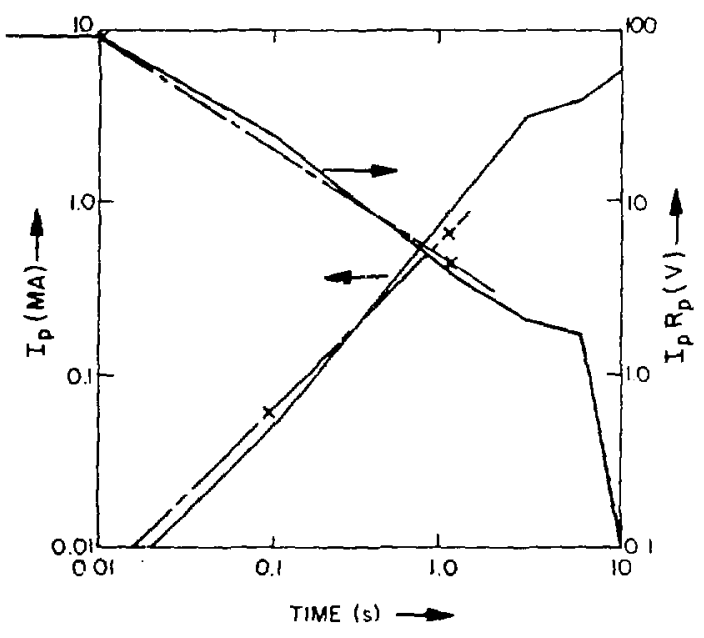

Fig. 2.

Reference time behavior with no radio-frequency (rf) assist during current rise.

magnetomotances taken over all blip coils above and below the midplane. and the blip energy for a blip pulse length $\tau_{h}=\tau_{d}+0.1 \mathrm{~s}$ is listed in Table IV, where $I_{b}$ and $W_{b}$ are the magnetomotance and energy-loss values at $t=\tau_{b}$. The blip voltage $V_{b}$ is the free variable chosen so the plasma current $I_{1} \simeq 60 \mathrm{kA}$ at $t=\tau_{\mathrm{b}}$, which corresponds to the desired $i_{1}=0.6 \mathrm{MA} / \mathrm{s}$. For Data Case $\mathbf{I}$, the energy losses and the volt seconds $a t=t_{b}$ are listed in Table $V$ for the elements of Table 1 and Fig. 1. The energy balance is satisfied within an error margin of $\left\langle 1 \mathrm{~kJ}\right.$. which is $10^{-5}$ of the total system energy, consistent with the programmed numerical error.

The 1.5-GJ loss in the TF cryostat is a conspicuous value, indicating a disadvantage of the high-voltage initiation method with no radio-frequency ( $\mathrm{r}$ ) assist. By adding an external coil set, strongly coupled to the TF cryostat. it may be possible to impress a current in opposition to the blip field. Such a coil addition might be particularly effective in conjunction with blip coils with improved plasma coupling. Plasma coupling can be achieved when the blip coils are moved radially outward within their present ( $r . \phi)$ plane (flux plot in Fig. 1).

\section{BLIP COIL ESTIMATE}

For Data Case I, four single blip coils, each built with 62 turns of a $20 \cdot \mathrm{kA}$ copper conductor with $50-\mathrm{A} / \mathrm{mm}^{2}$ current density, would be $\simeq 10 \mathrm{~cm}$ in the axial and $60 \mathrm{~cm}$ in the radial direction. Two coils would be mounted above the midplane, approximately as shown for coils 41 and 42 in Fig. 1; the two remaining coils would be used for the image below the midplane. If constant current (4.83 MAt) is assumed for $0.2 \mathrm{~s}$, the temperature rise from converting the joule loss to residual heat would be $3 \mathrm{~K}$ in the coils. The voltage per coil would be $8.5 \mathrm{kV}$, requiring a supplied peak power of $700 \mathrm{MW}$ for $0.19 \mathrm{~s}$. At the end of the blip, the blip coils would be shorted. For this condition, we extended to $4 \mathrm{~s}$ some of the computations corresponding to Fig. 4, using the $\mathrm{OH}$ and external field coils as the drivers. This verified that the blip coil current is reversed and continued to increase in the negative direction. Opening the blip circuits at the current zero would thus provide a useful operating procedure. The time from the start of the blip pulse to current zero is $=0.55 \mathrm{~s}$. The joule loss over the $0.55 \mathrm{~s}$ equals approximately that for the $4.83 \mathrm{MAt}$ over $0.2 \mathrm{~s}$ we used for estimating the coil temperature rise (that is. $3 \mathrm{~K}$ ).

This coil design is not optimized in any way and is given only to convey an idea of the general size of the blip circuit. Presumably, fewer turns would be selected to facilitate fabrication and maintenance.

\section{CONCLUSIONS}

Based on our results, we concluded that a blip coil should be provided for nonassisted initiation. and the blip coil should be large enough to provide for the delay caused by the vacuum vessel without insulating break. However. we do not know whether limiter impurity control will require more than $115 \mathrm{~V}$ for initiation with no assist. Before detailed preconceptual design is begun. the possibility of assisted initiation should be considered and the high-voltage blip eliminated if possible. Designing a well-conducting liner of the vacuum vessel or a uniform current path between adjacent segments of the vacuum vessel is practical and allows satisfactory initiation. The plasma initiation pulse requires less power and energy than those required for the plasma control circuit, as discussed in Ref. 4.

\section{ACKNOWLEDGMENT}

We thank Margaret Anderson for assembling the data for much of the computer work. 


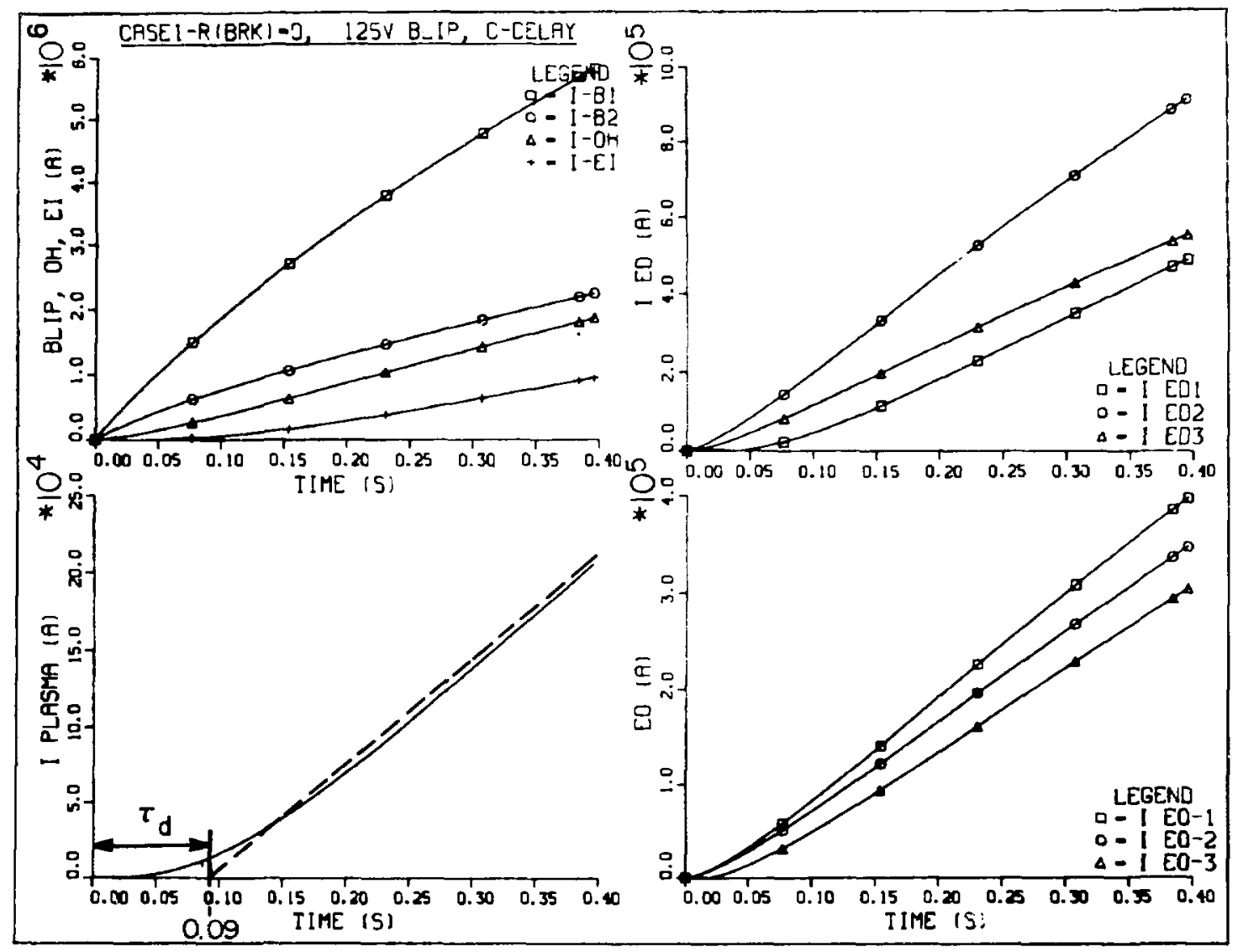

Fig. 3.

Currents in Data Case I, 125-V applied external voltage step, zero delay. The tangent on the plasma current defines $\tau_{d}$.

TABLE III

\section{ELECTROMAGNETIC DELAY TIME}

\begin{tabular}{|c|c|c|}
\hline Data Case & $\begin{array}{l}\text { Added Resistance } \\
\text { In Each Half-Space } \\
\text { With Respect To } \\
\text { Midplane } \\
(\mathrm{m} \Omega)\end{array}$ & $\begin{array}{c}\text { Delay } \tau_{d} \\
(s)\end{array}$ \\
\hline I & 0 & 0.090 \\
\hline II & 1.70 & 0.083 \\
\hline III & 8.50 & 0.072 \\
\hline IV & 17.5 & 0.056 \\
\hline v & 34.0 & 0.050 \\
\hline
\end{tabular}

TABLE IV

BLIP VALUES

\begin{tabular}{ccccc} 
Data Case & $\tau_{b}(s)$ & $V_{b}(V / t)$ & $I_{b}(M A t)$ & $W_{b}(M J)$ \\
\hline I & 0.190 & 137 & 4.83 & 68.8 \\
II & 0.183 & 124 & 4.16 & 52.2 \\
III & 0.172 & 122 & 3.89 & 44.8 \\
IV & 0.156 & 122 & 3.55 & 37.5 \\
V & 0.150 & 122 & 3.45 & 34.9
\end{tabular}




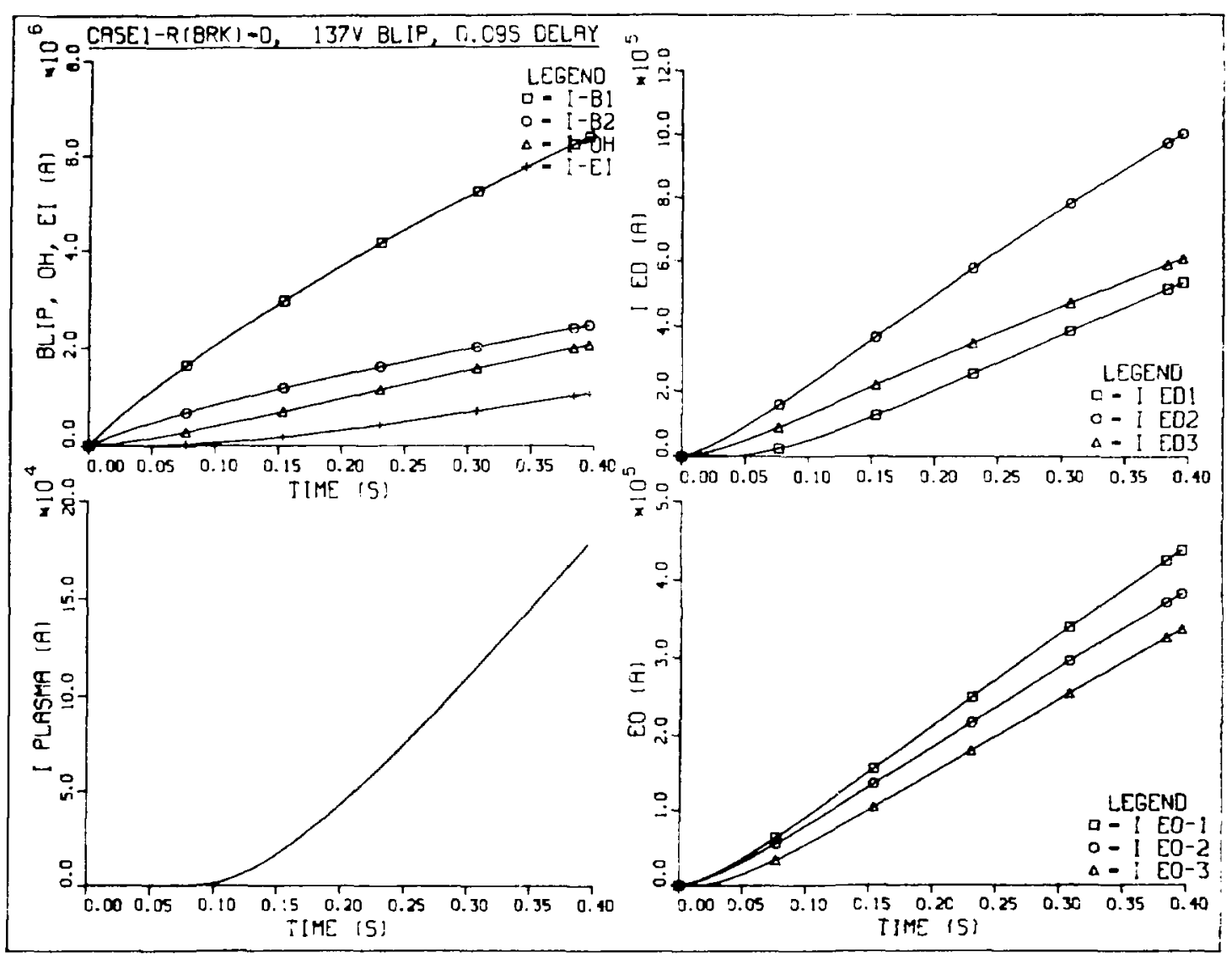

Fig. 4.

Active coil and plasma currents for Data Case I, $137 \mathrm{~V}$ applied voltage step. 


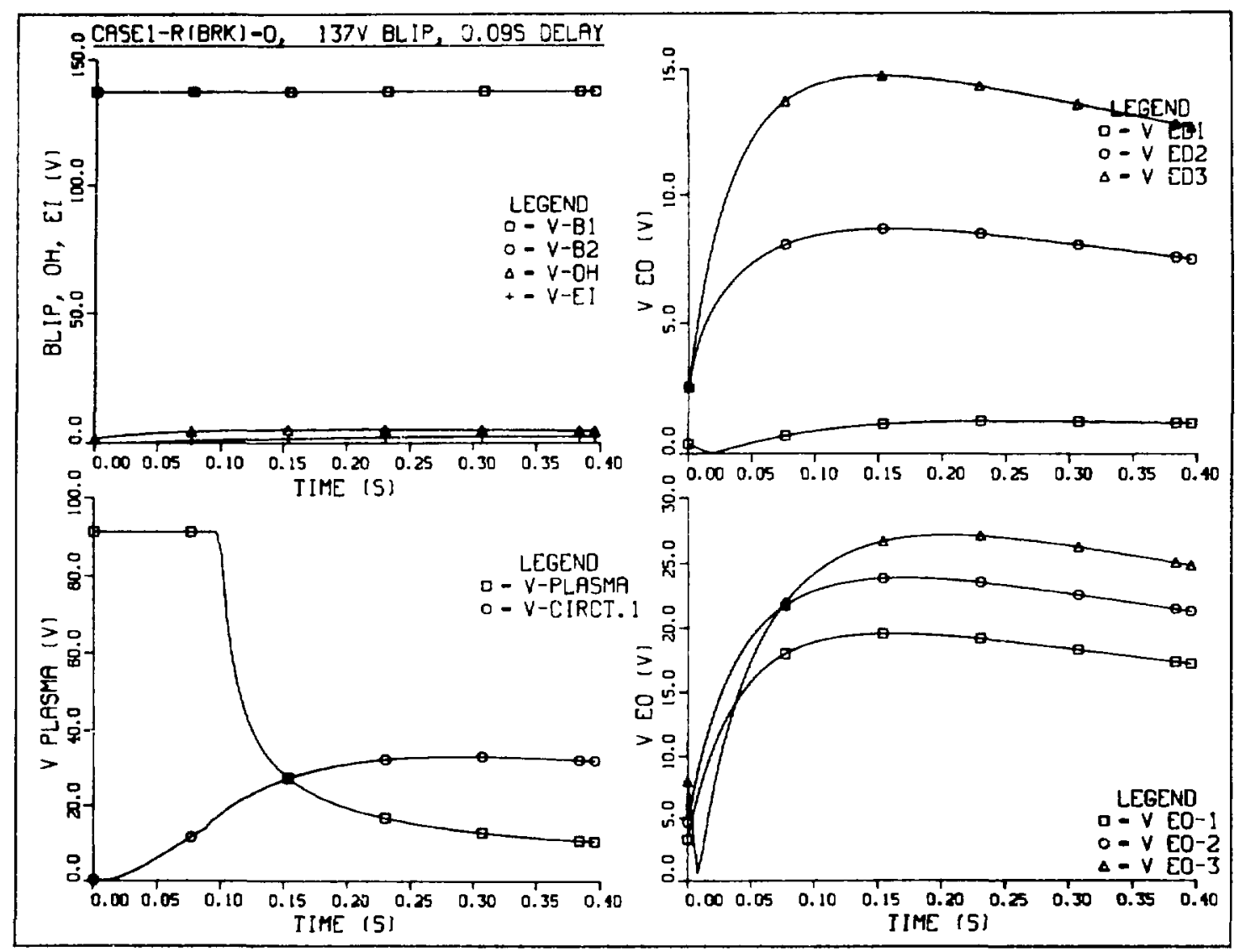

Fig. 5.

Data Case I active-coil and plasma electromotances (EMFs) and plasma voltage. For the two blip coils, I37-V applied external voltage step is plotted. 


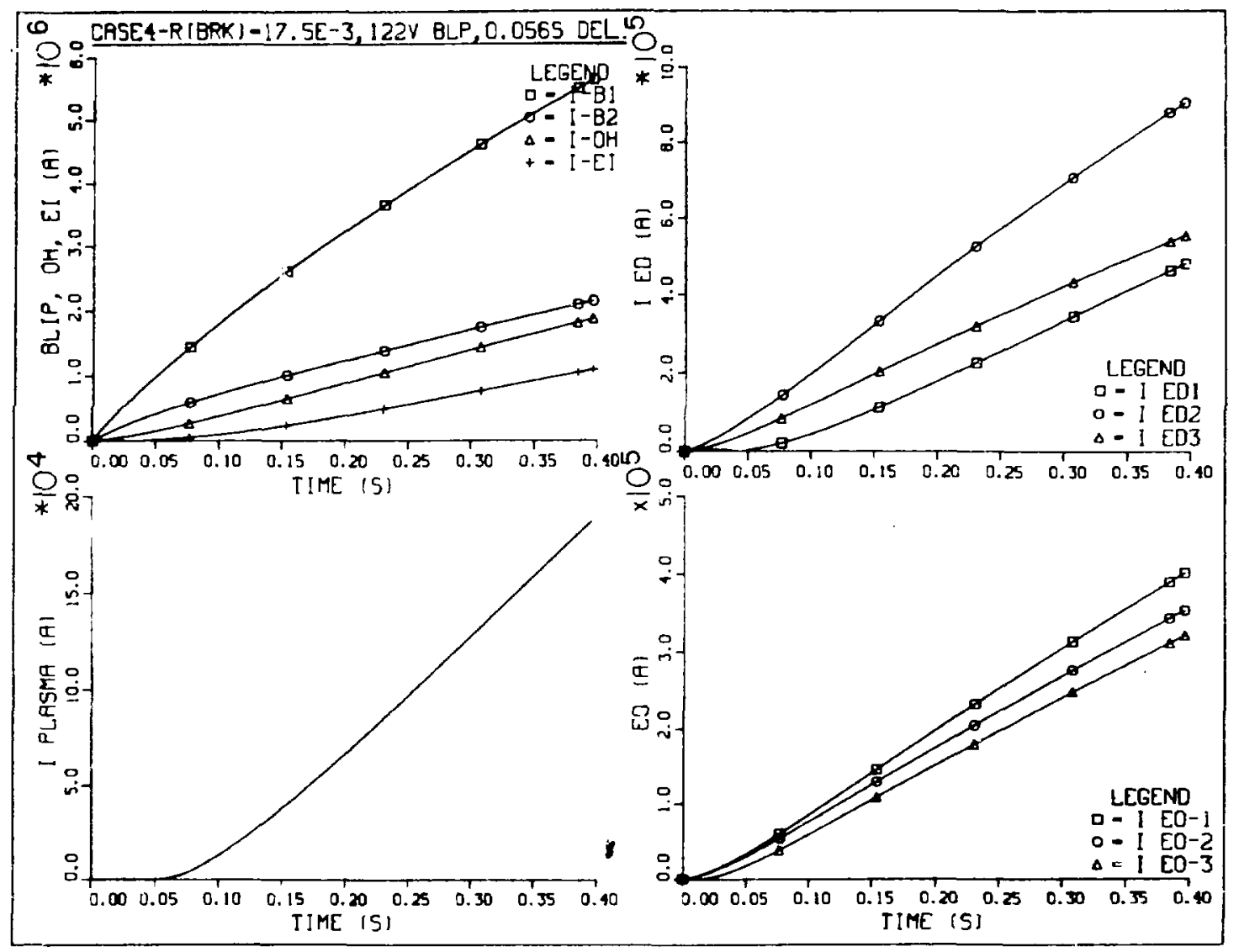

Fig. 6.

Active-coil and plasma currents for Data Case IV, 122-V applied voltage step. 


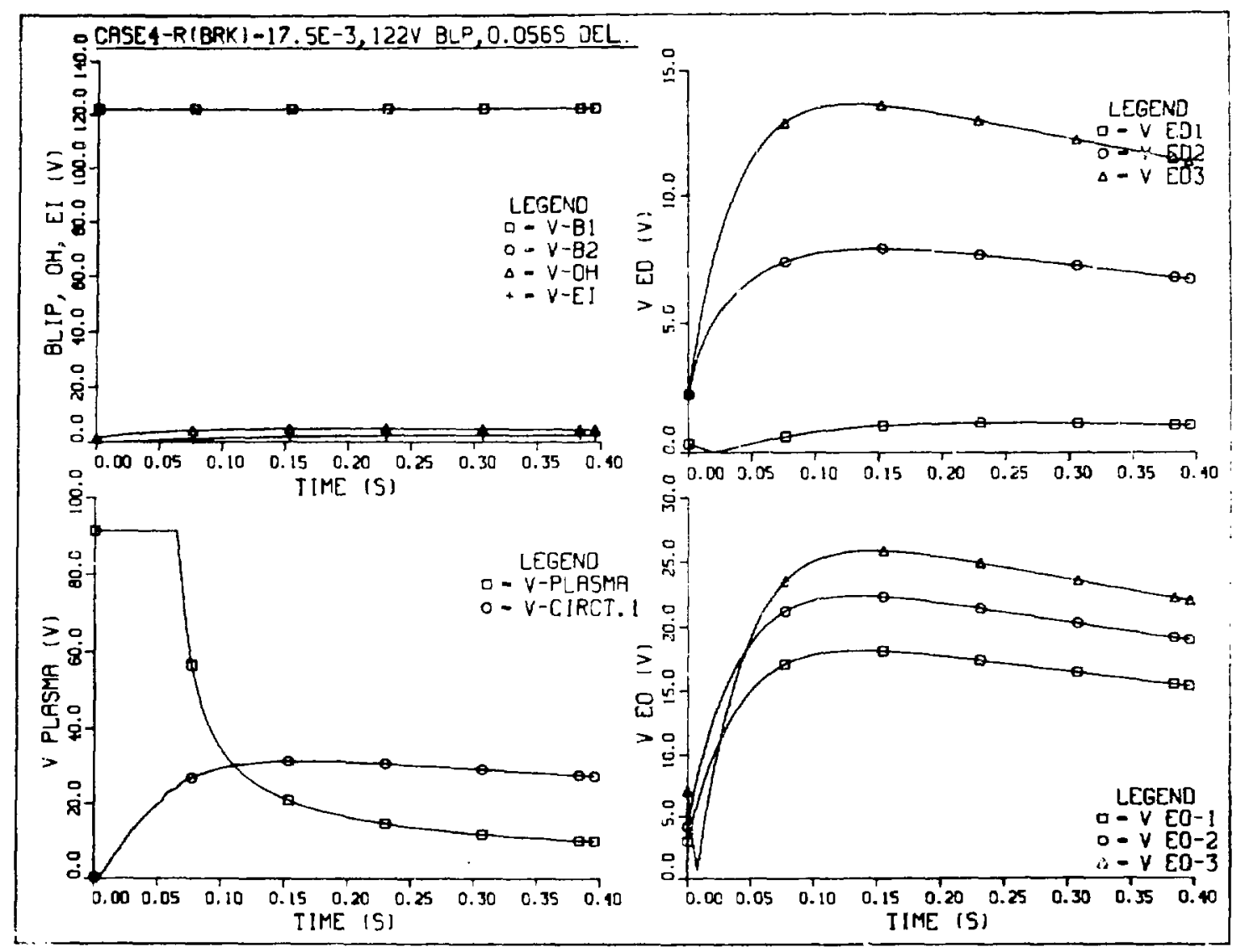

Fig. 7.

Data Case IV active-coil and plasma electromotances (EMFs) and plasma voltage. For the two blip coils, 122-V applied external voltage step is piotted. 
TABLE V

ENERGY LOSSES AND VOLT SECONDS AT $t=\tau_{b}$

\begin{tabular}{|c|c|c|c|c|}
\hline $\begin{array}{l}\text { Element } \\
\text { Number }\end{array}$ & $\begin{array}{c}\text { Element } \\
\text { Designation }\end{array}$ & $\begin{array}{l}\text { Loss } \\
(\mathrm{kJ})\end{array}$ & $\begin{array}{c}\text { Resistive Vs } \\
(\mathrm{Wb})\end{array}$ & $\begin{array}{c}\text { Inductive Vs } \\
\text { (Wb) }\end{array}$ \\
\hline 1 & Plasma (20 cm rad.) & 17.4 & 1.75 & 1.20 \\
\hline 2 & Bucking cylinder & 199 & 2.03 & 0.818 \\
\hline 3 & TF cryostat & 1486 & 16.56 & 2.59 \\
\hline 4 & Spool & 327 & 4.40 & 0.672 \\
\hline 5 & Inner wall & 374 & 4.73 & 0.753 \\
\hline 6 & Spool top. shell top & $4.52 \times 10^{3}$ & 34.1 & 5.07 \\
\hline 7 & Plasma shell & 408 & 15.4 & 1.69 \\
\hline 8 & Graphite & 21.1 & 4.69 & 0.0948 \\
\hline 9 & Water pipe & 153 & 6.11 & 1.040 \\
\hline 10 & Breeder blanket & 145 & 11.9 & 1.43 \\
\hline 11 & Outer shell & 361 & 10.0 & 1.61 \\
\hline 12 & $\mathrm{OH}$ Coil & $\mathbf{0}$ & 0 & 0.808 \\
\hline 13 & EI coil & 0 & $\mathbf{0}$ & 0.183 \\
\hline 14 & ED coils & 0 & $\mathbf{0}$ & 4.01 \\
\hline 15 & EO coils & 0 & $\mathbf{0}$ & 10.9 \\
\hline 16 & Blip coils & $8.28 \times 10^{1}$ & -4.74 & -55.9 \\
\hline 17 & OH cryostat & 8.99 & 0.496 & 0.0492 \\
\hline
\end{tabular}

\section{REFERENCES}

1. J. G. Murray. G. Bronner, and H. F. Vogel. "Elec tromagnetics in Structures of INTOR." USA INTOR report INTOR/ENG/80- 11

2. T. E. Shannon. "Report of Foreign Travel of T. E. Shannon, FEDC Systems Engineering Manager and USA INTOR Design Coordinator. Engıneering Division." Oak Ridge National Laboratory report ORNL/ENG/FTR-978 (November 14. 1980). Secs. 2.1.2. and 2.1.3.
3. Memorandum ETF M 80-PS-072 to C. A. Flanagan from Y-K. M. Peng, Engineering Test Facility Design Center. Oak Ridge National Laboratory. May 29. 1980, "Reference Time Behavior of Plasma Parame. ters in ETF/1NTOR."

4. George Bronner and D. Nelson, "FED Control Power." to be presented at Proc. Symp. Eng. Probl. Fusion Res., 9ih. Chicago. October 26-29. 1981. 